\title{
A Longitudinal Study on the L2 Word Depth Knowledge (Meaning and Collocation) Development in China from Dynamic Systems Theory Perspective
}

\author{
Ning Dali ${ }^{1}$ \\ ${ }^{1}$ Guangdong University of Foreign Studies, China \\ Correspondence: Ning Dali, Guangdong University of Foreign Studies, China. E-mail: \\ 200411216@oamail.gdufs.edu.cn
}

Received: March 10, 2018 Accepted: July 10, 2018 Online Published: July 11, 2018

doi: 10.5539/elt.v11n8p40 URL: http://doi.org/10.5539/elt.v11n8p40

\begin{abstract}
This study, adopting a longitudinal approach, traces the dynamic word knowledge development of two essential dimensions (meaning and collocation) both receptively and productively in Chinese context. Seven freshmen students (from the same class in a university in Guangzhou) of different language levels were selected to be observed of their English word knowledge development over one year's time. The results suggest that word knowledge develops with slowdowns and recessions and the dimensions of knowledge develop in an unbalanced way, an indication of the dynamic and complex nature of language learning. Receptive knowledge shows a much more active development than productive knowledge as it grows faster but with more losses as well. Collocation though always shows poorer acquisition results in the two tests, demonstrates a faster growth than meaning knowledge. As to the individual differences, participants who were tested as the higher level of learners did not always show better development in word depth knowledge during the year. The results also reveal the participants' learning preferences (e.g. passive learning style and active learning style). This study sheds light on the L2 vocabulary learning and teaching in Chinese context.
\end{abstract}

Keywords: word depth knowledge, longitudinal, receptive, productive, dynamic systems theory

\section{Introduction}

L2 word knowledge acquisition has always been the focus of SLA (second language acquisition) studies. In the previous decades a wide range of researches were conducted concerning L2 learners' receptive and productive word knowledge (Laufer, 1998; Schmitt, 2000; Webb, 2008; Zheng, 2009, Bell, 2009; Churchill, 2008; Li \& Schmitt, 2009; Zhang, 2015). The studies found that word knowledge develops in an incremental way and receptive knowledge is easier acquired than productive knowledge. Meanwhile, empirical studies on L2 word knowledge acquisition in China have switched from vocabulary size/breadth to vocabulary depth and the relations between the two (Tan, 2006; Cui \& Wang, 2006; Jiang, 2000; Zhang, 2008; Fu, 2009; Zheng, 2009). However, few are devoted to the discovery of what is happening in the acquisition process. As is discussed by Zheng (2011), most studies adopted the cross-sectional approach, which, though summarizes the general rules of language development, only reflects the learners' static learning state, like taking a photo o at a particular time point. However, longitudinal studies extend the research period and track the detailed change of the dynamic development, and hence better reveal the trend of language development.

Adopting the longitudinal approach, this study aims to discover the developmental changes of the most important dimensions (meaning and association) on individual learners both receptively and productively.

\section{Literature Review}

\subsection{Vocabulary Breadth Knowledge vs. Vocabulary Depth Knowledge}

Vocabulary breadth knowledge refers to "the number of words the meaning of which one has at least some superficial knowledge" (Qian, 2002). Breadth knowledge is fundamental in that knowing the form and meaning of a certain number of words is a prerequisite for unassisted comprehension of spoken and written discourses (Zhang, 2015).

Vocabulary breadth knowledge constitutes only one dimension of vocabulary knowledge, and depth of 
vocabulary knowledge is another important dimension that cannot be ignored (Nation, 2001; Qian, 2002; Schmitt, 2008, 2010). Depth of vocabulary knowledge usually refers to how well one knows a lexical item (Qian, 2002). Nation (2001) argued that knowing a word involves knowing not only its form (including spoken form, written form, and word parts) but also its meaning (including form and meaning, concept and reference, and associations) and use (including grammatical functions, collocations, and constraints on use). Studies (Qian, 2002; Schmitt, 2014) have found correlations between vocabulary breadth and vocabulary depth, but also pointed that they represent different aspects of word knowledge in that they shared little variance.

\subsection{Research on Vocabulary Depth}

\subsubsection{Dichotomous vs. Incremental}

Early studies have accepted recognition or production of a single meaning sense as evidence that word is "known". Reports of such studies often portray word knowledge as a 'yes' or 'no' condition implying that 'each word has just one meaning (Read, 1988).

The idea of the dichotomous nature of vocabulary acquisition encountered a lot of criticism in the later studies. Though researchers differ in their definition of vocabulary knowledge, it is nevertheless agreed by most that lexical knowledge is not an all-or nothing phenomenon, but involves degrees of knowledge. It is therefore advocated that vocabulary knowledge develops in an incremental way. Full mastery of a word requires more than just knowledge of its meaning and form (Nation, 1990; Richards, 1976).

\subsubsection{Word Knowledge Stages vs. Word Knowledge Continuum}

The most influential framework scale was developed by Wesche and Paribakht (1993) which consists of five stages of vocabulary knowledge. The five states are defined as statements that learners might make about their knowledge of particular word, but in the case of the more complex statements:

1) I don't remember having seen this word before;

2) I have seen this word before but I don't known what it means;

3) I have seen this word before and I think it means

4) I know this word. It means

5) I can use this word in a sentence. eg:

This vocabulary knowledge scale aims to describe what stages individual words pass through and to characterize where any particular word is positioned on the scale. Nevertheless, defining the stages boundaries may be problematic. Moreover, there is no principled way of determining the number of stages necessary to accurately describe the acquisition process. Besides, it is difficult to give balanced attention to both receptive and productive knowledge within a scale (Norbert, 1998). We may also find that the scale framework tends to focus on the development of meaning acquisition only. It seems other aspects of word knowledge are neglected.

Nevertheless, scholars are increasingly aware that word knowledge acquisition is a continuum consisting of various levels and dimensions of word knowledge. The process of learning a second language has often been described as the learner's process along the interlanguage continuum from a non-existent knowledge towards native-like competence without necessarily reaching it.

\subsubsection{Three Dimensions of Vocabulary Development}

In 1999, Henriksen proposed three dimensions for the description of lexical competence: partial to precise knowledge; depth of knowledge; receptive knowledge to productive use ability. Henriksen believes L2 learners' word knowledge is developed gradually, first partially, later toward a more precise direction. They will have different mastery of various kinds of word knowledge. It emphasizes that word knowledge is complex and consists of many types. Henriksen is among one of those many researchers who accept the division between reception and production. She agrees that there is a substantial difference in how well different lexical items are mastered in relation to ability to use the words in comprehension and production.

\subsubsection{Dynamic System Theory}

In recent years, the dynamic systems theory (DST) provides new perspective to the study of second language acquisition. It views language as a complex and dynamic system, within which every part (grammar and vocabulary and different dimensions of vocabulary) is interconnected. Due to this interaction, the development of language becomes unpredictable. Within the learning system, there are systems which support each other or, compete with each other. When competition takes place between subsystems, the growth of one may lead to the recession of another (Van Geert, 1991). 
Applied linguists have also focused on the dynamic development of other linguistic features, such as vocabulary development or loss (Meara, 2006), multilinguistic knowledge (Jessner, 2008), chunks learning (Verspoor \& Smiskova, 2012), and English speech (Polat \& Kim, 2014). The results indicate great variability in learners' language development as the variables interacts with internal and external factors of language learning system. A key concept in DST is 'phase transition', "the coming-into-existence of new forms or properties through ongoing processes intrinsic to the system itself" (Lewis, 2000). It reflects the discontinuous changes which could usher in a new stage when some new features are gained (Van Dijk \& Van Geert, 2007).

\subsection{Empirical Studies on Vocabulary Depth Knowledge}

Empirical studies concerning word depth knowledge were conducted in many countries to measure learners' vocabulary quality. Qian (2002) found that one's vocabulary depth knowledge is positively related to one's vocabulary size. However, research results proved that receptive knowledge (vocabulary breadth) develops at a different pace with that of productive knowledge (vocabulary depth) (Laufer, 1998; Liu, 2001) and it is argued that word knowledge does not develop in a linear way but with stage of 'stuck in a stagnant state'(Laufer \& Paribakht, 1998; Churchill, 2008; Tan, 2006; Wen, 2006;, Fu, 2009). Zheng (2015) conducted a longitudinal study within the framework of dynamic systems theory and found that the learners' L2 free productive vocabulary follows a fluctuating, non-linear and staged developmental pattern.

Though empirical studies on word knowledge development in China are on the rise in recent years, most mainly focus on the vocabulary learning strategies and vocabulary size acquisition of the learners. Moreover, the studies generate little understanding on the development of productive vocabulary. To further our understanding on how individual words are acquired and how acquisition of word knowledge develops within an individual, this study traces the development of the most important dimensions of word knowledge (meaning and collocation) in one year's time.

\subsection{Framework for the Present Study}

As is demonstrated below, word knowledge can be divided into two types-receptive knowledge and productive knowledge. Each type may consist of many dimensions, such as form, meaning, collocation, association etc. Moreover, learners develop their word knowledge from no acquisition stage to fully acquired stage, in a dynamic way (with stops and recessions) (see Figure 1).

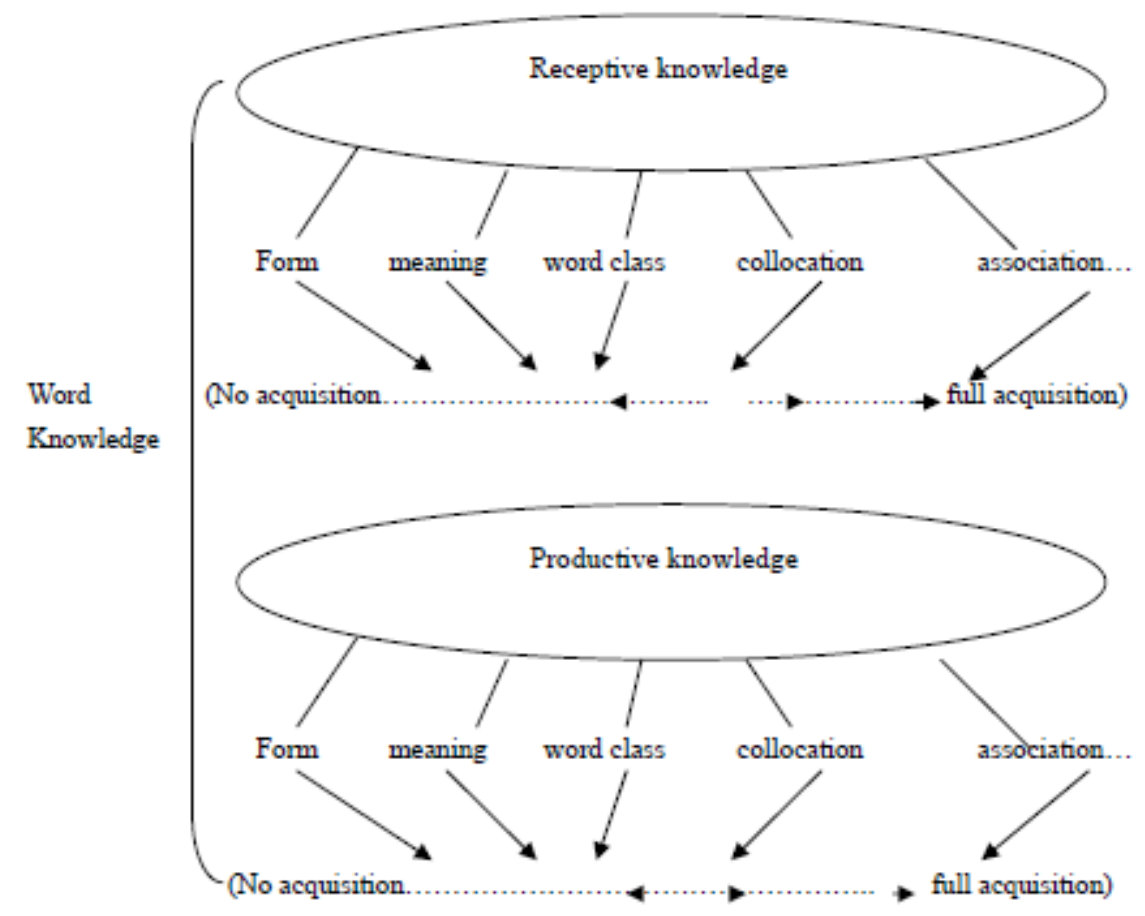

Figure 1. component knowledge of an individual word 


\section{The Study}

\subsection{Key Research Questions}

This empirical study aims to investigate the detailed features and developmental patterns of the learners' word knowledge (meaning and collocation) acquisition in Chinese context. It attempts to find the answers to the following specific questions:

1).What are the dynamic features of word knowledge development in this observation year?

2).What are the differences between receptive and productive knowledge development in one year's time?

$3)$. What are the differences between meaning and collocation knowledge development in one year's time?

4).What are the differences revealed by individual learners in this observation year?

\subsection{Research Design}

\subsubsection{Participants}

The seven participants in this study are second year students in School of English for International Business, GDUFS. All the participants in this study are selected from the same class to make sure that differences of the data are not the result of different teaching approaches and class environment. They are categorized into three groups (top-level, intermediate level, elementary level) according to their comprehensive English exam (held as their entrance examination at the beginning of the semester) result and the results of the vocabulary level test (conducted prior to the experiment).

\subsubsection{Instrument}

Twelve words from different word frequencies, all rich in meaning and collocation are selected to be the test words (selected from the two frequency dictionaries: Wang, 1991; Le, 1999). Two test papers are designed as the instrument of the study - a receptive knowledge test paper and a productive knowledge test paper each containing meaning part and collocation part. To test the meaning knowledge in the receptive paper, all meanings of the test words mixed with some other coined ones which serve as disturbance are given. Participants are required to pick out the right meanings without guessing and picking the ones that they are not sure of. To test the collocation knowledge in the receptive paper, sentences with all collocations of the test words, are given. Participants are required to translate the collocations either in Chinese or in English. In the production paper, participants are required to list the meanings they know about the test word and then make a sentence after each of the meaning listed as the proof of their correct understanding of the meanings (part of speech, use of the meaning, etc) in communicative context. After that is the collocation section where Chinese sentences are given. Below each sentence there is a part underlined and participants are required to translate the underlined part into English with the given test word.

\subsubsection{Procedure}

One week prior to the word knowledge test, a vocabulary size test was conducted to all the students in the class. Based on the test result and the result of their comprehensive English exam (held as their entrance examination at the beginning of the semester), seven students were selected to be the participants of this study. The paper for the measurement of productive knowledge was tested first so as to prevent the participants from being informed before the receptive knowledge test. Participants were gathered in a room and were seated apart to do the exercises in the paper. Those who finished earlier and had the intension to write down the words in the notebooks were abstracted from doing that. About two weeks after the productive knowledge test, the receptive knowledge test was conducted. The same tests will be conducted one year later to trace the development of such knowledge.

\section{Data Collection}

The answers will be categorized into four types and be given different marks: nil acquisition (NA), the meaning/collocation that is never able to be recognized/produced throughout the year, will be marked as 0 ; growth $(\mathrm{G})$, the meaning/collocation that was not able to be recognized/produced at the beginning of the observation year but is able to be recognized/produced at the end of the year, will be marked as +1 ; loss (L), the meaning/collocation that was able to be recognized/produced at the beginning of the observation year but not able to be recognized/produced at the end of the year, will be marked as -1 and preservation $(\mathrm{P})$, the meaning/collocation that is always able to be recognized/ produced throughout the year, will be marked as 1 .

The scores one participant gets in the part of meaning receptive knowledge of a word is the proportion of the number of the correct meaning answers divided by the number of all meanings of the word. For example, if there 
are altogether ten meaning senses of a word, and one gets 4 correct answers of them, the participant's meaning receptive knowledge on this word is $4 / 10$, i.e. 0.4 . It is almost the same case in calculating the collocation receptive knowledge. To get the average score of receptive meaning or collocation knowledge of all the 12 words, the percentages of each of the words will be summed up and then be divided by 12 .

As to the norming of the productive knowledge, the score one participant gets in meaning productive knowledge of a word is the proportion of the number of the correct production answers divided by the number of all possible answers. For example, if the word 'business' has ten meanings and the participant is able to produce 6 , the score for the meaning productive knowledge of 'business' is $6 / 10$, i.e 0.6 . It is almost the same case in norming the collocation productive knowledge. To get the average score of productive meaning or collocation knowledge of the 12 words, the percentages of each of the 12 words will be summed up and then be divided by 12 .

\section{Research Results}

\subsection{Comparison of Receptive vs. Productive Knowledge of Meaning}

Table 1. Comparison of receptive vs. productive knowledge of meaning for each subject

\begin{tabular}{lllllllll}
\hline $\mathrm{R}$ & $\mathrm{TK}$ & \multicolumn{2}{c}{ Nil Acquisition } & \multicolumn{2}{c}{ Growth } & \multicolumn{3}{c}{ Loss } \\
$\mathrm{S}$ & $\mathrm{R} \%$ & $\mathrm{P} \%$ & $\mathrm{R} \%$ & $\mathrm{P} \%$ & $\mathrm{R} \%$ & $\mathrm{P} \%$ & $\mathrm{R} \%$ & $\mathrm{P} \%$ \\
\hline $\mathrm{P} 1$ & 30 & 62 & 10 & 8 & 13 & 10 & 46 & 19 \\
P2 & 37 & 69 & 10 & 6 & 6 & 6 & 48 & 19 \\
P3 & 15 & 77 & 23 & 9 & 7 & 1 & 55 & 13 \\
P4 & 45 & 72 & 9 & 5 & 16 & 3 & 31 & 20 \\
P5 & 45 & 69 & 17 & 11 & 7 & 7 & 31 & 13 \\
P6 & 19 & 60 & 11 & 23 & 8 & 7 & 62 & 10 \\
P7 & 26 & 76 & 16 & 8 & 15 & 6 & 42 & 10 \\
Average & 31 & 69 & 14 & 10 & 10 & 6 & 45 & 15 \\
\hline
\end{tabular}

Note: TK: type of word knowledge;

R: result; P: participant

R: receptive knowledge

P: productive knowledge

As is shown in Table 2, all participants have loss as well as growth in their meaning knowledge development either receptively or productively, indicating that word knowledge does not grow continuously but with recessions. Word knowledge develops fluctuately.

In terms of meaning knowledge, all participants showed better acquisition result of receptive knowledge than productive knowledge either at the beginning or the end of the observation year. The part of meaning knowledge remaining unknown receptively (31\%) is smaller(less than half) than the part remaining unknown productively (69\%). And the percentage of the meanings remembered through the whole year is much larger $(45: 15$, about three times) than the meanings the learners are able to use. In other words, all participants are able to recognize more meanings of the words than to use them for communication.

If we draw a closer look at the table, we will find that most of the participants have more growth than loss in both types of meaning knowledge during the year, an indication that generally meaning knowledge grows as word breadth knowledge (vocabulary size) expands. However, some of the participants (P1 and P4) have greater loss (13\% and $16 \%$ respectively) than growth (10\% and $9 \%$ respectively) in receptive knowledge and some (P7) has similar loss to growth in both receptive (6\% and $8 \%$ respectively) and productive knowledge $(15 \%$ and $16 \%$ respectively), an implication that learners differ in the way of word knowledge development and to some learners, word depth knowledge may not grow along with word breadth knowledge. Therefore, vocabulary size test may not be able to reflect the details of how well one learns vocabulary, as it only tests the core meaning of a word.

According to the table, all participants (except P6) showed faster growth in receptive knowledge than in productive knowledge, which indicates a truth that receptive meaning knowledge is easier and faster to be learned than productive meaning knowledge. To the learners, it is easier to remember the meanings of words 
than to learn how to use them in context. This result well explains a phenomenon of English vocabulary learning among Chinese learners. To a great number of English learners in China, especially those who are of elementary or intermediate level, the most preferred learning approach is to read vocabulary books (where there are only English words with Chinese meanings or simple English explanation), as they will find soaring effect of their increase in recognizing new words in a very short period of time. And this is probably why so many Chinese ESL learners can read well but always struggle with choices of appropriate words in speaking or writing. Many, though have relatively large vocabulary, can only use very limited number of words for productive tasks (in both oral and written context).

An interesting finding regarding meaning knowledge is that receptive knowledge shows a much more active development than productive knowledge. Though the former demonstrates a faster growth than the latter, it shows a greater loss as well. Over half of the participants (P1, P3, P4, P6, and P7) have greater loss in receptive knowledge than in productive knowledge in one year's time and the other two participants (P1 and P5) have equal amount of loss in both type of knowledge. This proves a fact that productive knowledge is more stable than receptive knowledge - what is learned through practice is better remembered than what is learned through recognition. This result also suggests the importance and need of practice on the use of the newly learned words. In the real learning context, teachers and learners should create more opportunities of actively using the word knowledge so as to enhance learning quality.

Among the seven participants, participant 3 and participant 6 , both selected as intermediate level learners in word test, demonstrated quite special learning results in word meaning knowledge. Both of the participants show quite low (lower than all the others, even the advanced level participants) rate (15\% and $19 \%$ respectively, with the average of $31 \%$ ) of NA of receptive knowledge and high rate $(55 \%$ and $62 \%$, with the average of $45 \%)$ of preservation of such knowledge. This implies that P3 and P6 though tested as intermediate level learners are able to recognize more meanings of the words than those tested as advanced learners during the observation year, another piece of evidence that vocabulary size test only measures word breadth knowledge and cannot truly reflects the quality mastery of word knowledge. However, these two participants develop their meaning knowledge in completely different ways/styles, though both showing huge gap between receptive and productive knowledge. According to the table, P3 has $77 \%$ of productive NA (the meanings unable to use) through the whole year, the worst among all participants. What's more, P3 shows a much faster growth in receptive meaning knowledge $(23 \%$, much more than all other participants, as the average is $14 \%)$ than productive meaning knowledge (9\%, almost the average of all participants). All these results imply that P3 has outstanding ability in remembering the meanings of the words but rather poor ability in using them. Contrary to P3, P6 has $60 \%$ of productive NA (the meanings unable to use) through the whole year, the worst acquisition learner among all participants. In addition, P6 shows a much faster growth in productive meaning knowledge ( $23 \%$ over double of the average $10 \%$ of all participants) than receptive meaning knowledge $(11 \%$, almost the average of all participants). Hence, P6 is better using the meanings than recognizing them. From what is analyzed, P3 is a typical passive learner, who does better job in recognizing than producing, while P6 is a typical active learner, who is better at using than remembering knowledge.

\subsection{Comparison of Receptive vs. Productive Knowledge of Collocation}

Table 2. Comparison of receptive vs. productive knowledge of collocation for each subject

\begin{tabular}{|c|c|c|c|c|c|c|c|c|}
\hline \multirow{2}{*}{$\begin{array}{l}\mathrm{R} \\
\mathrm{S}\end{array}$} & \multicolumn{2}{|c|}{ Nil Acquisition } & \multicolumn{2}{|c|}{ Growth } & \multicolumn{2}{|l|}{ Loss } & \multicolumn{2}{|c|}{ Preservation } \\
\hline & $\mathrm{R} \%$ & $\mathrm{P} \%$ & $\mathrm{R} \%$ & $\mathrm{P} \%$ & $\mathrm{R} \%$ & $\mathrm{P} \%$ & $\mathrm{R} \%$ & $\mathrm{P} \%$ \\
\hline P1 & 35 & 77 & 19 & 7 & 10 & 4 & 36 & 13 \\
\hline $\mathrm{P} 2$ & 41 & 73 & 23 & 9 & 6 & 4 & 31 & 14 \\
\hline P3 & 52 & 83 & 16 & 6 & 11 & 1 & 21 & 11 \\
\hline P4 & 47 & 82 & 21 & 9 & 10 & 4 & 22 & 5 \\
\hline P5 & 56 & 80 & 13 & 8 & 7 & 3 & 24 & 9 \\
\hline P6 & 57 & 87 & 12 & 9 & 6 & 1 & 23 & 3 \\
\hline P7 & 57 & 83 & 12 & 9 & 8 & 3 & 23 & 6 \\
\hline Average & 50 & 81 & 16 & 8 & 8 & 3 & 26 & 9 \\
\hline
\end{tabular}


We can see from the above table that with respect to collocation knowledge, all participants showed better acquisition result of receptive knowledge than productive knowledge either at the beginning or the end of the observation year. The part of collocation knowledge remaining unknown receptively is much smaller than the part remaining unknown productively. And the collocations of a word remembered through the whole year are much more (26:9, about three times) than the collocations the learners are able to use. In other words, the participants are able to recognize more collocations of the words than to use them for communication. Moreover, receptive knowledge develops better than productive knowledge since the former demonstrates larger (almost double) growth than the latter. This also proves that in the dimension of collocation knowledge, receptive knowledge is easier and hence faster to be learned by the learners. Once again, receptive knowledge shows a more active development than productive knowledge as the former suffers greater loss as well, which proves again that knowledge learned through use/output is more stable than that learned passively (by input).

Also should be noted is that the acquisition level of collocation knowledge is in line with tested vocabulary level--advance level learners have better acquisition than intermediate level learners and the latter, better than elementary learners. Evidence is that the part of unknown collocation knowledge of the top level learners, either receptively or productively, is smaller than that of the intermediate level learners and even smaller than the elementary level learners. The percentage of the knowledge known through the whole year by the top level learners is larger than that of the intermediate level learners and even larger than the intermediate level learners. What's more, the growth rate of receptive knowledge in collocation is in line with vocabulary level--advance level learners learn faster of new collocations than intermediate level learners and even faster than elementary learners. The three levels of learners don't show much difference in the growth rate of productive knowledge as all of them learns slowly in this type of knowledge.

Though differences in collocation dimension are not as distinctive as in meaning knowledge, P3 and P6 still show different preferences in learning. P3 shows a $16 \%$ of growth in recognizing new collocations, average of all participants, but only $6 \%$ of growth in using the collocations. Contrarily, P6 only shows a $12 \%$ growth in recognizing new collocations, the lowest of all, but the highest growth of $9 \%$ in using new collocations. Hence, in collocation dimension, P3 still prefers learning by remembering while P6 prefers learning by using.

\subsection{Comparison of Meaning vs. Collocation of Receptive Knowledge}

Table 3. Comparison of meaning vs. collocation of receptive knowledge for each subject

\begin{tabular}{|c|c|c|c|c|c|c|c|c|}
\hline \multirow{2}{*}{$\begin{array}{l}\mathrm{TK} \\
\mathrm{S}\end{array}$} & \multicolumn{2}{|c|}{ TR Nil Acquisition } & \multicolumn{2}{|l|}{ Growth } & \multicolumn{2}{|l|}{ Loss } & \multicolumn{2}{|c|}{ Preservation } \\
\hline & MR \% & CR \% & MR \% & CR \% & MR \% & CR \% & MR \% & CR \% \\
\hline $\mathrm{P} 1$ & 30 & 35 & 10 & 19 & 13 & 10 & 46 & 36 \\
\hline $\mathrm{P} 2$ & 37 & 41 & 10 & 23 & 6 & 6 & 48 & 31 \\
\hline P3 & 15 & 52 & 23 & 16 & 7 & 11 & 55 & 21 \\
\hline P4 & 45 & 47 & 9 & 21 & 16 & 10 & 31 & 22 \\
\hline P5 & 45 & 56 & 17 & 13 & 7 & 7 & 31 & 24 \\
\hline P6 & 19 & 57 & 11 & 12 & 8 & 6 & 62 & 23 \\
\hline P7 & 26 & 57 & 16 & 12 & 15 & 8 & 42 & 23 \\
\hline Average & 31 & 49 & 14 & 17 & 10 & 8 & 45 & 26 \\
\hline
\end{tabular}

Viewed from the perspective of receptive knowledge, all participants showed a better acquisition result of meaning knowledge than collocation knowledge in the observation year as fewer meanings remain unknown than collocations and more known through the year.

Generally, with regard to receptive knowledge, collocation develops better than meaning knowledge as participants showed larger growth in collocation than meaning (17:14 on average), especially the top level participants whose growth in collocation doubles that in meaning knowledge. This may indicate that when vocabulary level develops to a certain degree, learners display better ability in learning collation knowledge than meaning knowledge. Moreover, most participants showed greater loss in meaning than collocation, which implies that meaning knowledge development is more active than collocation knowledge. 


\subsection{Comparison of Meaning vs. Collocation of Productive Knowledge}

Table 4. Comparison of meaning vs. collocation of productive knowledge for each subject

\begin{tabular}{|c|c|c|c|c|c|c|c|c|}
\hline \multirow{2}{*}{$\mathrm{TK}_{\mathrm{S}}^{\mathrm{TK}} \mathrm{TR}$} & \multicolumn{2}{|c|}{ Nil Acquisition } & \multicolumn{2}{|c|}{ Growth } & \multicolumn{2}{|c|}{ Loss } & \multicolumn{2}{|c|}{ Preservation } \\
\hline & MP & $\mathrm{CP}$ & MP & $\mathrm{CP}$ & MP & $\mathrm{CP}$ & MP & $\mathrm{CP}$ \\
\hline $\mathrm{P} 1$ & 62 & 77 & 8 & 7 & 10 & 4 & 19 & 13 \\
\hline $\mathrm{P} 2$ & 69 & 73 & 6 & 9 & 6 & 4 & 19 & 14 \\
\hline P3 & 77 & 83 & 9 & 6 & 1 & 1 & 13 & 11 \\
\hline P4 & 72 & 82 & 5 & 9 & 3 & 4 & 20 & 5 \\
\hline P5 & 69 & 80 & 11 & 8 & 7 & 3 & 13 & 9 \\
\hline P6 & 60 & 87 & 23 & 9 & 7 & 1 & 10 & 3 \\
\hline P7 & 76 & 83 & 8 & 9 & 6 & 3 & 10 & 6 \\
\hline Average & 69 & 81 & 10 & 8 & 6 & 3 & 15 & 9 \\
\hline
\end{tabular}

As is shown in the above table, results concerning productive knowledge are rather poor and don't show as big differences as in Table 4 when comparisons are made in receptive knowledge. In terms of productive knowledge, all participants showed a better acquisition result of meaning knowledge than collocation knowledge as fewer meanings remain unknown than collocations and more known through the year. Meanwhile, meaning productive knowledge shows a more active development than collocation productive knowledge. As we can see from the table, though, generally, the participants showed a slightly larger growth in meaning ( $10 \%: 8 \%$ on average), they showed apparently even a larger loss (6\%:3\%) in it as well. Among all the participants, P6 showed the best growth productively in both meaning and collocation knowledge, once again proved to be good at producing knowledge, either in dimension of meaning or collocation.

\section{Major Findings and Pedagogical Indications}

The major findings from the longitudinal study are summarized as the following points:

1) Word knowledge development is a dynamic process. Learners develop their word knowledge in a non-linear way. As is demonstrated in the results, all participants have an overall increase in the word knowledge tested (meaning, collocation, receptive knowledge and productive knowledge). However, their development in word knowledge is accompanied by small losses (generally less than $10 \%$ ) through the whole year, indicating slowdowns and recessions during the learning process. This result suggests that vocabulary learning is a process that requires repetitive effort to reinforce the memory of the knowledge.

2) Receptive knowledge demonstrated better learning results than productive knowledge as the former shows a larger growth than the latter either in meaning or collocation, which indicates that knowledge learned through memorizing is easier and faster to be acquired than knowledge learned through using. This result well explains the reason why Chinese students regard reciting vocabulary list as the priority of learning English language. However, receptive knowledge shows a much more active development than productive knowledge as though it grows faster, it suffers greater loss as well. It proves the idea that the best way to learn is through using. The result sheds light on English teaching in Chinese context: learners should be reminded that instead of reciting vocabulary lists, reading more extensively to know the different uses of such words and more importantly, using them frequently in written and spoken tasks helps more in increasing and stabilizing one's word knowledge. Accordingly, teachers are encouraged to create more chances for students to practice their productive word knowledge.

3) Meaning shows better acquisition result than collocation as there is more knowledge remain known and less knowledge remain unknown in the former through the year. However, Collocation knowledge develops faster than meaning knowledge in that the former shows greater growth but smaller loss during the year, especially the top-level participants, who demonstrated much faster growth in collocation than meaning. This might indicate that learners, whose vocabulary size develop to a certain level (e.g. sophomores), become more sensitive in learning collocation knowledge than other dimensions of word knowledge. This is what DST called 'transition phrase'. According to DST, there are always competitions between subsystems: the growth of one subsystem 
may lead to the recession of another. The fast loss of meaning knowledge might be the result of a faster growth in collocation as learners who pay much attention to the learning of one dimension may not be able to take care of others.

4) Generally collocation development is in line with one's vocabulary breadth (the larger one's vocabulary size is, the better collocation knowledge one develops). Meaning knowledge develops in a much more complex way. It doesn't show a clear correlation with the vocabulary breadth as participants in lower level may demonstrate better word knowledge development (larger growth, smaller loss). This result suggests that vocabulary size test cannot truly reflect word knowledge proficiency as it cannot measure the knowledge quality. And this unbalanced development in different types and dimensions of word knowledge reveals the dynamic and complex nature of language learning system.

5) This longitudinal study also reveals the distinctive learning styles of the participants. For example, P3 (intermediate level participant), who shows the best acquisition and growth in receptive knowledge but rather poor development in productive result is a typical passive learner (who prefers learning through memorizing), while P6 (intermediate level participant) who shows the best acquisition and growth in productive knowledge but rather poor development in receptive result is a typical active learner (who prefers learning through using). This suggests that even if learners come from the same background (with the same mother language and similar education background), they may not develop their knowledge the same way. It is important that teaching activities are planned catering to different learning situations of the learners.

\section{Conclusion}

Vocabulary has always been an important and difficult part of English language learning for Chinese students. Recent years have witnessed a growth in the research of vocabulary learning in Chinese context, most of which focused on vocabulary breath or vocabulary learning strategy by employing a cross-sectional approach. To trace the detailed word knowledge development pattern of individual learners, this study observes the meaning and collocation development of seven participants in one year's time. The result shows that vocabulary learning is a dynamic and discontinued process. Different types and dimensions of word knowledge do not develop in a balanced way, an indication of the dynamic and complex nature of language learning. Learners should be reminded the importance of creating chances meeting and using the newly learned words till they are stably acquired. Compared with receptive knowledge, productive knowledge develops stably and the acquired productive knowledge is seldom lost. Therefore, more opportunities should be given to the practice of using the knowledge. Receptive knowledge develops more actively as it develops faster than productive knowledge but shows more losses during the learning process. Another interesting finding is that though all participants demonstrated poorer leaning results in collocation, during this one year observation time, they showed faster growth in collocation knowledge than meaning knowledge, an indication that the second year in college might be the time when the learners expand their word knowledge mainly in collocation dimension. Sufficient supply of learning materials for collocation expansion during this period of time might promote a more efficient vocabulary learning result. This study also discovers different learning styles of the participants, which is reflected by their different leaning result, an indication (as is suggested by DST) that language learning is complex process and its development is influenced by interactions of many factors, such as grammar, native language, learning habit, etc. This result also reminds that teachers should plan their teaching schedule according to students' need and preference of learning.

\section{Acknowledgments}

This study is funded by Projects of Educational Research in Humanities and Social Sciences Studies in colleges and universities in Guangdong province 2017GXJK043.

\section{References}

Bell, H. (2009). The messy little details: a longitudinal case study of the emerging lexicon. In T. Fitzpatrick, \& A. Barfield (Eds.), Lexical Processing in Second Language Learners: Papers and Perspectives in Honor of Paul Meara (pp. 111-127). Multilingual Matters, Bristol, England. https://doi.org/10.21832/9781847691538-011

Churchill, E. (2008). A dynamic systems account of learning a word: from ecology to form relations. Applied Linguistics, 29(3), 339-358. https://doi.org/10.1093/applin/amm019

Cui, Y. Y., \& Wang, T. S (2006). Developments and relationships of receptive vocabulary size, productive vocabulary size and depth of vocabulary knowledge. Modern Foreign Languages, 29, 392-400.

Fu, Y. P., Cui, Y. Y., \& Chen, H. (2009). A Longitudinal Study of the Developmental Patter of SL Mental Lexicon. 
Foreign Language and Literature Studies, 2, 6-23.

Henriksen, B. (1999). Three dimensions of vocabulary development. Studies in Second Language Acquisition, 21, 303-317. https://doi.org/10.1017/S0272263199002089

Jessner. (2008). A DST model of multilingualism and the role of metalinguistic awareness. The Modern Language Journal, 92(2), 270-283. https://doi.org/10.1111/j.1540-4781.2008.00718.x

Jiang, N. (2000). Lexical representation and development in a second language. Applied Linguistics, 21, 47-77. https://doi.org/10.1093/applin/21.1.47

Laufer, B. (1998). The development of Passive and Active Vocabulary in a Second Language: Same or Different? Applied Linguistics, 19(2), 255-271. https://doi.org/10.1093/applin/19.2.255

Lei, X. Y. (1999). Frequently used English Words. Shanghai: Shanghai Jiao Tong University Press.

Li, J., \& Schmitt, N. (2009). The acquisition of lexical phrases in academic writing: a longitudinal case study. Journal of Second Language Writing, 18, 85-102. https://doi.org/10.1016/j.jslw.2009.02.001

Liu, S. L. (2002). Dimension Development and Acquisition Patterns of L2Word Knowledge. Journal of PLA University of Foreign Languages, 2, 66-69

Lewis. (2000). The promise of dynamic systems approaches for an integrated account of human development Child development, 71(1), 36-43

Marjorie, W., \& Paribakht, T. S. (1996). Assessing second language vocabulary knowledge: depth versus breadth. The Canadian modern language review, 53(1), 13-40. https://doi.org/10.3138/cmlr.53.1.13

Meara. (2006). Emergent properties of multilingual lexicons. Applied Linguistics, 27(4), 620-644. https://doi.org/10.1093/applin/aml030

Nation, I. S. P. (1990). Teaching and learning vocabulary. New York: Newbury House.

Nation, I. S. P. (2001). Learning Vocabulary in Another Language. Cambridge: Cambridge University Press. https://doi.org/10.1017/CBO9781139524759

Paribakht, T. S., \& Wesche, M. (1993). Reading comprehension and second language development in a comprehension-based ESL program. TESL Canada Journal, 11, 9-29. https://doi.org/10.18806/tesl.v11i1.623

Polat \& Kim. (2014). Dynamics of complexity and accuracy: A longitudinal case study of advanced untutored development. Applied Linguistics, 35(2), 184-207. https://doi.org/10.1093/applin/amt013

Qian, D. D. (2002). Investigating the Relationship Between Vocabulary Knowledge and Academic Reading Performance: An Assessment Perspective. TESL Canada Journal, 52, 513-536. https://doi.org/10.1111/1467-9922.00193

Read, J. (1988). Measuring the vocabulary knowledge of second language learners. RECL Journal, 19(2), 12-25.

Richards, J. C. (1976). The role of vocabulary teaching. TESOL Quarterly, 10, 77-89. https://doi.org/10.2307/3585941

Schmitt, N. (1998). Tracking the Developmental Acquisition of Second Language Vocabulary: A Longitudinal Study. Language learning, 48, 281-317. https://doi.org/10.1111/1467-9922.00042

Schmitt, N. (1998). Measuring collocational knowledge: key issues and an experimental assessment procedure. ITL International Journal of Applied Linguistics, 119, 27-47. https://doi.org/10.1075/itl.119-120.03sch

Schmitt, N. (2000). Vocabulary in Language Teaching. Cambridge University Press, Cambridge, England.

Schmitt, N. (2014). Size and depth of vocabulary knowledge: What the research shows. Language Learning, 64, 913-951. https://doi.org/10.1111/lang. 12077

Tan, X. C. (2006). A study on Chinese EFL learners' productive vocabulary development. Foreign Language Teaching and Research, 38(3), 202-207.

Van, G. (1991). A dynamic systems model of cognitive and language growth. Psychological Review, 98, 3-53. https://doi.org/10.1037/0033-295X.98.1.3

Van, D., \& Van, G. (2007). Wobbles, humps and sudden jumps: A case study of continuity, discontinuity and variability in early language development. Infant and Child Development, 16(1), 7-33. https://doi.org/10.1002/icd.506 
Webb, S. A. (2008). Receptive and productive vocabulary sizes of L2 learners. Studies in Second Language Acquisition, 30, 79-95. https://doi.org/10.1017/S0272263108080042

Wang, T. F. (1995). English collocation dictionary. Modern Press.

Wen, Q. F. (2006). A longitudinal study on the changes in speaking vocabulary by English majors in China. Foreign Language Teaching and Research, 38, 189-195.

Xian, Z., \& Xiao, F. L. (2015). The Relationship Between Vocabulary Learning Strategies and Breadth and Depth of Vocabulary Knowledge. The Modern Language Journal, 99(4), 740-753. https://doi.org/10.1111/modl.12277

Zheng, Y. Y. (2009). Exploring Chinese EFL learners' receptive and productive vocabulary knowledge: implications for EFL vocabulary teaching. The Journal of Asia TEFL, 6, 163-188.

Zhang, S. J. (2008). The Developmental Course of the L2 Mental Lexicon: A Longitudinal Study. Journal of Sichuan International Studies University, 24, 120-124.

Zheng, Y. Y. (2011). Towards a Dynamic Systems Theory approach to second language acquisition research. Modern Foreign Languages, 3, 303-309.

Zheng, Y. Y. (2015). A longitudinal study on free productive vocabulary development from Dynamic Systems Theory perspective. Foreign Language Teaching and Research, 2, 276-288.

\section{Copyrights}

Copyright for this article is retained by the author(s), with first publication rights granted to the journal.

This is an open-access article distributed under the terms and conditions of the Creative Commons Attribution license (http://creativecommons.org/licenses/by/4.0/). 